Montana Tech Library

Digital Commons@ Montana Tech

Fall 9-25-2018

\title{
STAIRWAY UNIFORMITY MEASUREMENT: WHAT LATERAL LOCATION SHOULD BE MEASURED
}

Roger C. Jensen

Montana Tech of the University of Montana

Lee Calf Looking

Montana Tech of the University of Montana

Follow this and additional works at: https://digitalcommons.mtech.edu/shih

Part of the Occupational Health and Industrial Hygiene Commons

\section{Recommended Citation}

Jensen, Roger C. and Calf Looking, Lee, "STAIRWAY UNIFORMITY MEASUREMENT: WHAT LATERAL LOCATION SHOULD BE MEASURED" (2018). Safety Health \& Industrial Hygiene. 31.

https://digitalcommons.mtech.edu/shih/31

This Article is brought to you for free and open access by the Faculty Scholarship at Digital Commons @ Montana Tech. It has been accepted for inclusion in Safety Health \& Industrial Hygiene by an authorized administrator of Digital Commons @ Montana Tech. For more information, please contact sjuskiewicz@mtech.edu. 


\section{STAIRWAY UNIFORMITY MEASUREMENT: WHAT LATERAL LOCATION SHOULD BE MEASURED?}

Roger C. Jensen, Montana Technological University, Butte MT

Lee Calf Looking, Former Graduate Student of Montana Tech

An experimental study sought to extend understanding of the nosing-to-nosing method for measuring dimensions of steps in a stairway. A human factors expert retained to assist an attorney in a case of injury or death from a stairway fall needs to decide the lateral location for taking the measurements. This experiment was undertaken to provide experts with a justifiable basis for choosing the location. Using a campus stairway and 16 student subjects, a randomized complete block experiment compared their lateral location while performing four tasksascending with or without the handrail, and descending with or without the handrail. Results showed task significantly affected lateral distance. Based on findings from this experiment, and some professional judgment, the authors provide recommended ranges for the lateral locations for measuring step dimensions - 30 to $38.5 \mathrm{~cm}$ for ascending, and 19 to $28 \mathrm{~cm}$ for descending.

\section{INTRODUCTION}

Numerous human factors forensic professionals support attorneys in stairway fall litigation (Cohen and Cohen, 2017; Johnson, 2017). Typical involvement follows a serious injury. The human factors expert investigates physical features of the stairway, characteristics of the victim, and environmental attributes (Cohen, LaRue, and Cohen, 2009). A core allegation in post-injury litigation is the allegation of a defect in the stairway. One important defect is the lack of uniform step dimensions. In order for the human factors expert to testify about this issue, courts require measurements using scientifically sound methods (Daubert vs. Merrill Dow Pharmaceuticals, 1993). A sound method is available for measuring the effective dimensions of the riser and tread of steps, but the method does not provide guidance on the lateral location within a flight to make the measurements. In cases where the victim died or otherwise cannot describe how and why they fell, the human factors expert needs to both decide on the lateral location, and have a justification for that decision. This paper addresses that issue.

\section{Stairway Fall Injury Frequency}

Stairway falls occur in many locations. The United Kingdom's Health and Safety Executive published a literature review on the topic of falls on stairways (Scott, 2005). Some findings reported in the literature review address the location of stairway falls. According to data from multiple countries, homes are the most common sites of stairway falls (Japan 68\%, United States $80 \%$, and Sweden $72 \%$. For workplace falls, other record systems provide more information about stairway fall injuries and fatalities.

The U. S. Bureau of Labor Statistics reported that in 2008 there were 700 fatal falls in U. S. workplaces, and four percent of these were falls down stairs.

Cohen, Templer, and Archea (1985) reported an analysis of workers' compensation claims in California and Ohio. Out of 688 stairway fall claims for which direction of travel was indicated, $636(92 \%)$ occurred while descending. A similar percentage using Japanese records was reported by Nagata (1991).

\section{Objectives}

This project addressed an unresolved issue involving methods for measuring step uniformity. Leading experts on stairway safety agree that lack of step uniformity within a flight contributes to risk of a misstep. The traditional method of measuring step dimensions using ruler held vertically for riser and horizontally for tread depth, has limited precision (Johnson, 2005). A 
relatively new method for more precisely measuring step dimensions is the nosing-to-nosing method (Johnson, 2005; Pauls, 1998). It has been shown to be repeatable and reproducible (Hicks, Jensen, and Adams,

2013). An issue in applying the method is lack of guidelines for the lateral location to measure. That location depends on where stairway users ascend and descend relative to the width of the steps. As part of a litigated case, Harvey Cohen conducted an observational study of people descending a public stairway in order to determine the lateral distance between the handrail center and the mid-line of the person's body (Cohen, 2000). He found the median was $44 \mathrm{~cm}$ and the distribution was large.

This impetus for undertaking this project was to extend Cohen's observational study by using a designed experimental approach. In order to focus the experiment, we only included ascending and descending with the handrail on the person's right side. This approach eliminates stairway users who take a diagonal route, a central path, or a path with the handrail on their left side.

The primary objective was to develop recommendations for the lateral location to measure step dimensions for post-fall litigation purposes. Human factors investigators should find this useful in those cases where other evidence does not clearly indicate the actual location of the victim's path. In ' order to achieve that objective, this intermediate step was to experimentally determine if the lateral distance between participants and handrail is affected by their direction of travel and use of a handrail.

\section{METHODS}

\section{Experimental Design}

To accomplish the primary objective, the investigators planned a randomized complete block experiment, with the dependent variable being lateral distance (LD) between the inner edge of the handrail and the mid-point of the stair user's knees. The treatment variable of interest was task performed. The four tasks are presented in Figure I.

\begin{tabular}{c|c|c|} 
& \multicolumn{1}{c}{ With } & Without \\
\multirow{4}{*}{ Ascending } & Handrail & \multicolumn{1}{c}{ Handrail } \\
\cline { 2 - 3 } Descending & Task A & Task B \\
\cline { 2 - 3 } & Task C & Task D \\
\cline { 2 - 3 } & &
\end{tabular}

Figure 1. The four experimental tasks.

The initial statistical procedure was a two-way, balanced analysis of variance (ANOVA) with participants serving as a blocking factor. As described by Rossi (2010), the model for this ANOVA is

$$
L D t i=n+p i+t i+e i i
$$

where:

LD; $y$ is the value of LD obtained for they'th participant doing the /th task,

// is the overall mean of the measured LDs,

$P j$ is the effect of theyth participant (the blocking variable),

$/ /$ is the effect of the rth task, and $£ /$; is the mean square error of the ANOVA model for the value of LD in theyth block with the /th task. 
The order of the four tasks was balanced using a pair of Latin Squares. Thus, each subject was assigned a personal order. This experimental design allowed for the ANOVA to test the null hypothesis that the mean LDs of the four tasks are equal, versus the alternative that at least two of the means differ. The plan was that if the null hypothesis is rejected, various post- hoc analyses would address possible effects of handrail use, direction of travel. Body Mass Index, and gender.

\section{Stairway Site}

A stairway located on the Montana Tech campus provided a suitable location. It had low usage, good lighting, and space for locating video equipment without obstructing people using the hallway. A photo is in Figure 2.

\section{Participants}

Prior to recruiting participants, the University of Montana Institutional Research Board approved the study (Approval

Number 196 -14). A call for volunteers was extended to students majoring in occupational safety and health as well as industrial hygiene. To provide gender balance, the first eight women volunteers and the first eight male volunteers were chosen. Their demographics are provided in Table I.

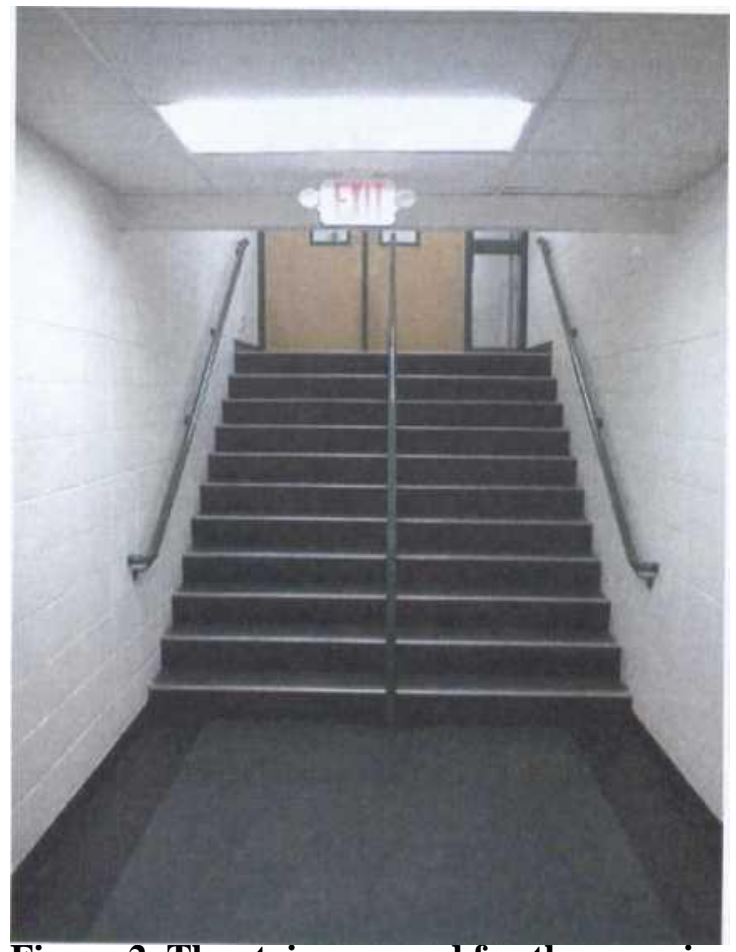

Figure 2. The stairway used for the experiment 
Table 1. Demographics of the participating volunteers

\begin{tabular}{lcccc}
\hline Parameter & Age & $\begin{array}{c}\text { Weight } \\
(\mathrm{kg})\end{array}$ & $\begin{array}{c}\text { Height } \\
(\mathrm{m})\end{array}$ & $\begin{array}{l}\text { BMI } \\
\text { t' }\end{array}$ \\
\hline Mean & 26.25 & 76.9 & 1.717 & 25.78 \\
Max & 44 & 122 & 1.846 & 36.63 \\
Min & 20 & 43.6 & 1.564 & 17.82 \\
Median & 24 & 76.9 & 1.710 & 25.03 \\
S.D. & 7.308 & 21.3 & 0.095 & 5.52 \\
\hline
\end{tabular}

$\mathrm{t} \mathrm{BMI}$ is Body Mass Index

\section{Procedures}

The investigators established a visible distance marker on the stairway by taping a yellow tape measure onto a riser. When a subject arrived for their scheduled trials, they met in a room with the student investigator, Lee Calf Looking. He explained the experiment, noted risks and benefits, and obtained their signature on the approved consent form. He then obtained information on age and gender, followed by measuring the height and weight of each participant. They were then instructed to perform the four tasks in the order specially prepared for them. For both ascent and descent, they were instructed to have the handrail on their right side. A video camera was located on a tripod placed in one of two spots on the floor facing the stairway. In order to obtain an orthogonal view, one location was used for ascents, another for descents.

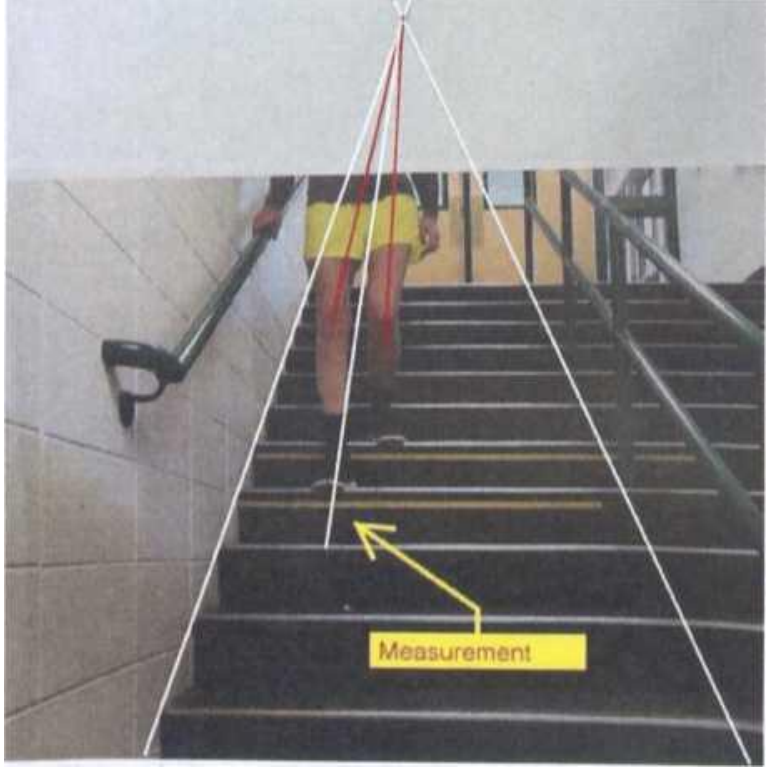

Figure 3. Example of how the mid-knee location was determined.

After printing the images, the perspective point was established as indicated by the left and right lines in Figure 3. The middle line was drawn from the perspective points through the midpoint between the subject's knees. A visible tape measure was used to read the distance from the 
wall as shown. This LD between the subject's knees and the inside edge of the respective handrail was then determined.

\section{RESULTS}

The boxplot in Figure 4 depicts the spread of the 64 LD values with the second and third quartiles boxed. Values ranged from $10 \mathrm{~cm}$ to $60 \mathrm{~cm}$. The first, second, and third quartile values were $22.5,28.5$, and $36.3 \mathrm{~cm}$. The mean, standard error, and standard deviation were $30.03,1.39$

Duxpiuı U1 Lu (CiI)

and $11.14 \mathrm{~cm}$.

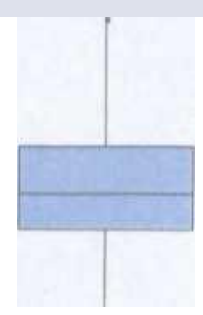

\section{Initial ANOVA}

Figure 4. Boxplot of all 64 lateral distances.

Results of the initial ANOVA presented in Table 2 indicate that LD values were significantly affected by the tasks $(p<0.005)$. Thus, the null hypothesis was rejected in favor of the alternative hypothesis that at least two of the treatment means are not equal. The subjects are blocking variables, and therefore not of interest (Rossi, 2010).

Table 2. Results of Initial ANOVA

\begin{tabular}{|c|c|c|c|c|}
\hline Source & Df $\quad$ SS & MS & $\mathrm{F}$ & $\mathrm{P}$ \\
\hline Task & 33111.72 & 1037.24 & 19.34 & $<0.001$ \\
\hline Participa & 152293.23 & 152.8 & \multirow[t]{2}{*}{2.85} & \multirow[t]{2}{*}{0.003} \\
\hline Ërror & 452413.80 & 53.64 & & \\
\hline Total & 637818.75 & & & \\
\hline
\end{tabular}

\section{Task Comparisons}

Means for each of the four tasks are reported in Table 3, and boxplots are shown together in Figure 5. Ascending with the handrail (task A) had the largest mean LD at $40.2 \mathrm{~cm}$, while descending without using the handrail (task D), had the smallest mean LD at $20.5 \mathrm{~cm}$. The means of subject-specific differences $(\mathrm{N}=16)$ in the right column provide data for comparing LD when using the handrail versus not using the handrail. For both ascending and descending, participants were further from the handrail when using the handrail. The means of subjectspecific differences $(\mathrm{N}=16)$ in the bottom row provide data for comparing LD when ascending versus descending. For both using and not using the handrail, participants were spaced further from the handrail while ascending. 
Table 3. Fourfold Tabic of Mean LDs $(\mathrm{cm})$ of the Four Tasks with Differences

\begin{tabular}{|c|c|c|c|}
\hline & $\begin{array}{l}\text { Handrai } \\
\text { With }\end{array}$ & $\begin{array}{l}\text { I Usage } \\
\text { Withou }\end{array}$ & $\begin{array}{r}\text { Mean } \\
\text { Difference }\end{array}$ \\
\hline Ascending & 40.2 & 30.0 & $10.2^{*}$ \\
\hline $\begin{array}{l}\text { Descending } \\
\text { Mean } \\
\text { Difference }\end{array}$ & $\begin{array}{r}29.3 \\
10.9^{*}\end{array}$ & $\begin{array}{l}20.5 \\
9.5^{*}\end{array}$ & $8.8^{*}$ \\
\hline
\end{tabular}

To learn which tasks had different mean LDs, a General Linear Model in Minitab 17 was used. The confidence intervals for all pairwise differences are presented in Figure 6. If the confidence intervals do not cross the zero line, there is a significant difference. All pairs are significantly different except the pair LDB and LDc.

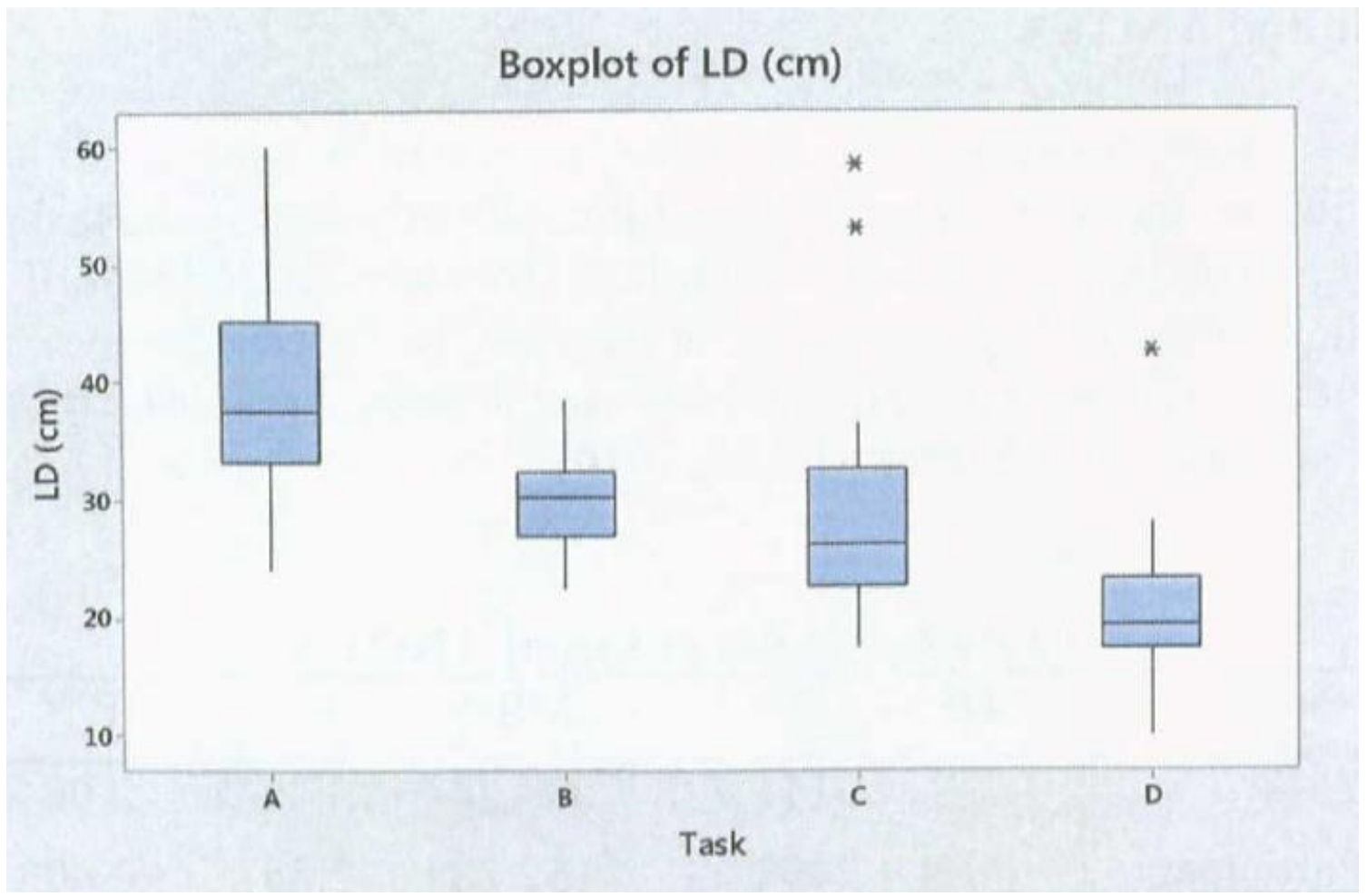

Figure 5. Boxplot for quartiles of $L D$ values for each of the four tasks 


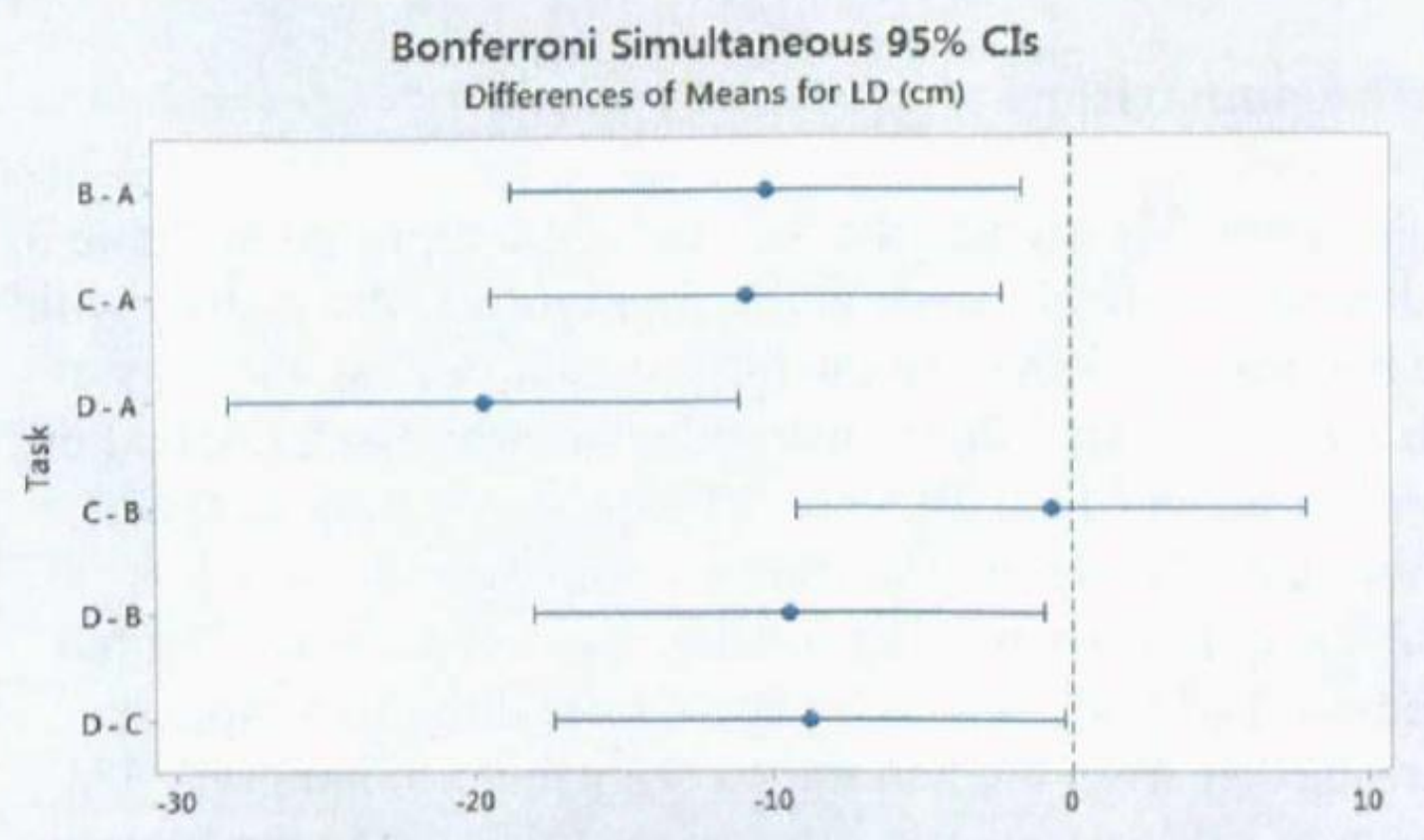

If on interval does not cantain zero, the corresponding means are significantly different.

Figure 6. Pairwise comparisons of mean LDs of the tasks.

Following up on these findings, the investigators examined the distribution of LD values for ascending tasks combined, and the values for descending tasks combined. For the ascending tasks (A and $\mathrm{B})$, the interquartile range is from 30 to $38.5 \mathrm{~cm}$. For the descending tasks $(\mathrm{C}$ and $\mathrm{D})$, the interquartile range is from 19 to $28 \mathrm{~cm}$. These ranges were considered for making recommendations.

\section{Comparison with Prior Study}

A comparison of descending data from this study and that reported by Cohen (2000) is in Table 4. Because Cohen measured LD from the center of the handrail, the LD values for this study were adjusted to do the same. Table 4 presents percentiles of descent data in inches and in centimeters.

\section{Effects of Other Variables}

Analyses for possible effects of other variables on LD were examined. The order of performing the four tasks had been randomly assigned, so no effect was anticipated. For ascending, there was no significant difference in using the handrail first versus second. The same conclusion applied to descending. 
Table 4. Comparison of $\mathrm{LD}$ Distributions for Descending Tasks by Cohen and This Study.

\begin{tabular}{lrlrr} 
& \multicolumn{2}{c}{ LD in Inchest } & \multicolumn{2}{c}{ LD in } \\
\cline { 2 - 5 } Percenti & \multicolumn{2}{c}{ This } & This \\
le & Cohen & Study & Cohen & Study \\
\hline 100 & 58.0 & 23.6 & 147.3 & 61.0 \\
90 & 32.5 & 17.7 & 82.5 & 45.0 \\
75 & 22.5 & 12.0 & 57.1 & 30.5 \\
50 & 17.5 & 9.9 & 44.4 & 25.2 \\
25 & 10.0 & 8.1 & 25.4 & 20.7 \\
10 & 8.0 & 7.7 & 20.3 & 19.5 \\
0 & 7.0 & 4.9 & 17.8 & 12.5 \\
\hline
\end{tabular}

t Lengths based on LD from center of handrail.

The possible effects of BMI on LD were examined using a data plot and linear regression. BMI is the ratio of a person's weight (kilograms) to their squared height (meters squared). The thought behind this was that a larger BMI means greater girth, which in turn limits how close the individual can get to the handrail. The hypothesis was that as BMI increases, LD will also increase. A data plot showed wide distribution about the best fit linear regression line, $\mathrm{LD}=$ $19.31+0.416$ BMI. The slope $(0.416)$ was not significantly different from zero $(p=0.111)$. Thus, this post-hoc analysis neither supports nor disputes the proposition that as BMI increases, the LD of stairway users increases.

The possible effects of gender on LD were examined using ANOVA. Table 5 reports the means LD of each gender for each task. Each mean is for eight participants. Results showed no significant effect $\{p=0.46)$. The task-specific differences in the right column do not indicate a meaningful pattern of gender difference.

Table 5. Gender-Specific Mean LD by Task

\begin{tabular}{lrrc}
\hline \multicolumn{4}{c}{ Mean LD $(\mathrm{cm})$} \\
Task & Females Males & Difference \\
\hline A & 42.1 & 38.3 & 3.8 \\
B & 28.0 & 32.0 & -0 \\
C & 27.9 & 30.7 & -2.8 \\
D & 17.9 & 23.2 & -5.3 \\
\hline Column & 29.0 & 31.1 & -2.1 \\
\hline
\end{tabular}

\section{DISCUSSION}

The primary objective was to develop recommendations for the lateral location for measuring step dimensions. In order to achieve that objective, an intermediate step was to experimentally determine if the lateral distance between participants and handrail is affected by their direction of travel and use of a handrail.

The first point of this discussion addresses how this study differs from the earlier study by Cohen (2000). Our study included ascent and descent whereas the observational study only included descent. Our study included only stairway uses with the handrail on the participant's right side, whereas the observational descending pathways were chosen freely by those observed. In our study, we defined LD from the inside edge of the handrail to themidpoint between the subject's knees, whereas the observational study measured from the middle of the handrail to the center of the 
person's body. In our study, the subjects were aware of being observed, whereas those in Cohen's study were not. Another possible factor was the difference in widths of the stairways. Our stairway was $120.8 \mathrm{~cm}$ (47.5 inches) whereas as Cohen's stairway was $167.6 \mathrm{~cm}$ (66 inches). All these differences explain why findings of the two studies differ.

Findings of this study indicate that lateral distance from the handrail is affected by the direction of travel and by use of the handrail. The greatest lateral distance was for ascending with the handrail. The shortest lateral distance was for descending without the handrail.

Limitations of the study include the following. The participants were not chosen randomly from a larger population of students, or from a large population of stairway users. For this reason, extrapolation to a larger population should be done cautiously. Another limitation was the participants were instructed to use the handrail on their right side for two of the four tasks. People in general do not typically receive any such instruction. Additionally, our study only included stairways with a handrail.

\section{Recommendations}

The authors share the opinion that measuring from the inside edge of the handrail is preferable to measuring from the center of the handrail. Our reasoning is that handrails come in many shapes, it is the inside edge that limits how close the user can get.

For investigating a stairway fall, the expert needs to choose at least one lateral location for measuring step uniformity; and they will need a basis for that choice. In cases where testimony or other evidence points to a particular site of a trip, stumble, or slip, the choice should be clear. But in cases lacking that information, we offer two recommendations.

First, we recommend measuring LD from the rail on the person's right side because that is the convention in the United States. Second, we recommend measuring step dimensions within the interquartile range of LDs found in our study. Thus, if the victim was ascending, measure within the range 30 to $38.5 \mathrm{~cm}$ from the inside edge of the handrail. If the victim was descending, measure within 19 and $28 \mathrm{~cm}$ from the inside edge of the handrail. Although these ranges do not include every stairway user, we suggest it provides a research-based guideline that is preferable to a lateral location selected arbitrarily by the forensic investigator.

\section{ACKNOWLEDGMENTS}

The graduate studies of Lee Calf Looking were made possible by support from the Sloan Scholar, Alfred P. Sloan Foundation's Indigenous Graduate Partnership (SIGP)

Program, awarded in 2013-2014. The grant number under

which this award was made is 2013 SIGPT. The authors

greatly appreciate that generous support.

\section{REFERENCES}

Cohen, FI. H. (2000). A field study of stair descent. Ergonomics in Design, 8(2), 11-15. doi: $10.1177 / 106480460000800203$

Daubert vs. Merrill Dow Pharmaceuticals, Inc. 509 U.S. 579 (1993).

Cohen, H. H. \& Cohen, J. (2017). Fall forensics: Principles and applications. In: H. Hsiao (Ed.), Fall Prevention and Protection: Principles, Guidelines, and Practices (pp. 389-401). Boca Raton, FL: CRC.

Cohen, J., LaRue, C. S., \& Cohen, H. H. (2009). Stairway falls: An ergonomics analysis of 80 cases. Professional Safety, 54(1), 27-32.

Cohen, H. H., Templer, J., \& Archea, J. (1985). An analysis of stair accident patterns. Journal of Safety Research, 16, 176-181.

Hicks, C. L., Jensen, R. C., \& Adams, J. M. (2013). Stairway step dimensions: Replication of a measurement system study. Proceedings of the Human Factors and Ergonomics Society 57, 575-579. doi:10.1177/1541931213571123

Johnson, D.A. (2005). Error in stair measurements. Ergonomics in Design, 13(2), 18-22. 
Johnson, D.A. (2017). Case studies of falls on stairs. In: H. Hsiao (Ed.), Fall Prevention and Protection: Principles, Guidelines, and Practices (pp. 403-414). Boca Raton, FL: CRC.

Nagata, H. (1991). Occupational accidents while walking on stairv/ays. Safety Science, 14(3-4): 199-211.

Pauls, J. (1998). Techniques for evaluating three key environmental factors in stairway-related falls. Proceedings of the Human Factors and Ergonomics Society, 42, 1630.

Rossi, R. J. (2010). Applied Biostatistics for the Health Sciences, p. 508. Hoboken, NJ: Wiley.

Scott, A. (2005). Falls on Stairways - Literature Review. Report No. HSL/2005/10, Buxton, Derbyshire, SK17, 19JN: Health and Safety Laboratory.

U.S. Bureau of Labor Statistics (2008). Fatal falls by type of fall 2008 Chart 26. Washington DC: Bureau of Labor Statistics 
